\title{
A Parametric Model for Accident Prediction along Akure-Owo Road, Ondo State, Nigeria.
}

\author{
Aderinola O.S. ${ }^{1}$, Laoye, A.A. ${ }^{2}$ and Nnochiri, E.S. ${ }^{3}$ \\ ${ }^{1,2}$ Department of Civil and Environmental Engineering, Federal University of Technology, Akure (FUTA), \\ Nigeria. \\ ${ }^{3}$ Department of Civil and Environmental Engineering, AfeBabalola University, Ado-Ekiti (ABUAD), Nigeria.
}

\begin{abstract}
The research looked into developing a parametric model for predicting accidents at specific locations along Akure-Owo road based on a previous study by Olabisi (2012).The reconnaissance survey of the road and the identified accident vulnerable points along the road was carried out and the factors aiding the occurrence of accidents as elucidated by Olabisi (2012) were isolated as Spot speed[S], Pavement condition[P], Condition of shoulder[C], Width of the road[W], Elevation(super)/cambering[E], Gradient[G] and Accident Vulnerability[AV] which form an acronym SPCWEG-AV. The spot speed in each of the locations was got by measuring a $100 \mathrm{~m}$ length and noting the time vehicles covered the distance. The pavement and shoulder conditions were evaluated by experienced raters who drove over them at specified speed to score their conditions. The width of the road, the elevation(super)/cambering and the gradient(horizontal) were measured using tape, twine and plumb. When the analyzed data from the investigated factors from the field were imputed into SPCWEG-AV Rating system and Weights, the index (which is a multiplication of the rating and weight) of each of the parameters was got and the addition of these indices produced what is called Total SPCWEG-AV Index(T.SPCWEG-AV.I) which defines the degree of accident vulnerability of the point in question. The higher the T.SPCWEG-AV.I is, the more vulnerable the location is. The results show seven accident prone areas as identified by Olabisi (2012). They are: Seebi Holdings Area (Ch.1+100), Olu Foam Area (Ch.1+200), Shagari Area (Ch.1+300), Ado-Ekiti junction Area (Ch.2+200), Federal Govt. Girl's College Area (Ch.3+000), FUTA Guest House Area (Ch.3+500) and Ogbese Market Area (Ch.25+800). FUTA Guest House Area (Ch.3+500) and Ogbese Market Area (Ch.25+800) have the highest number of accidents each having 44. Ado-Ekiti junction Area (Ch.2+200) and Seebi Holding Area (Ch.1+100) have accident occurring 36 and 35 times respectively. The result also shows that FUTA Guest House Area (Ch.3+500) and Ogbese Market Area (Ch.25+800) have the highest T.SPCWEG-AV.I of 74 and 76 respectively and other points show similar pattern. It is therefore, reasonable to conclude that the parametric model can replicate and predict the occurrence of accidents along Akure-Owo road and other roads with similar features. It is recommended that the results of researches should be put to use and that agencies in charge of roads should ensure proper design, supervision and construction and to make sure the roads are properly maintained.
\end{abstract}

Index Terms: Parametric model, Akure-Owo road, Spot speed[S], Pavement condition[P], Condition of shoulder[C], Width of the road[W], Elevation(super)/cambering[E], Gradient[G], Accident Vulnerability[AV], Total SPCWEG-AV Index.

\section{Introduction}

Traffic composition of a pavement is very dynamic because of the steady migration of the rural population to cities and the rapid development of the industries, establishments, educational and business activities. Road traffic accidents occur worldwide but the incidence is more in developing countries (Asogwa, 1978; Oderoet al., 1997). Annually, it causes about 1.2 million deaths globally. Road traffic accident is a leading cause of death in adolescents and young adults worldwide. Majority of mortalities and morbidities occur in developing countries (Oderoet al., 1997; Ekereet al., 2005; Labingoet al., 2009).According to Oyedepo and Makinde (2009), road traffic accidents are becoming very common and are robbing the Nation of its valuable human resources. He noted that the implication of this leads to both social and economic trauma. He emphasized that the road accident can be curbed by mainly educating the drivers on defensive driving skills and also the enforcement of traffic laws. Every year more than 1.17 million people die in road crashes around the World, $70 \%$ of these occur in developing countries. Globally, every 10 million people are crippled or injured each year, $65 \%$ of deaths involved pedestrians, $35 \%$ of pedestrians are children. Nigeria loses about 80 billion Naira annually to road accidents. Of all subjects that are involved in road traffic accidents in Nigeria, 29.1 per cent suffer disability and 13.5 per cent are unable to return to work (Labingoet al., 2009).In Nigeria, about 300,000 persons lost their lives in 1,000,000 road accidents between 1960 and 2005-a period of 45years, while over 900,000 person suffered various degrees of injuries within the same period Federal Road Safety Commission (FRSC \&Balogun, 2006). The accident situation is more serious in Nigeria because of the rapid growth of motor 
vehicles in the past few years and the inadequacy of many of our roads. Road traffic crashes (RTC) are having a worsening effect on our society and economy. Among all accident, road traffic accidents claim the largest toll of human life and tend to be the most serious problem World over (Kualet al., 2005). The accident situation is more serious in Nigeria because of rapid growth of motor vehicles, in the past few years and inadequacy of many of our roads, behavior of road users and the transport system also influence the level of accident. According to the causes of accident being interplay of a variety of factors, the analysis of accident data presents formidable problems. Qualitative methods of analysis of accident can provide insight into the causes that contributed to accident and can often help to identify the black spots on the street. More recently, emphasis has shifted to the application of statistical technique in planning and analyzing experiments into the effectiveness of accident prevention measures and development of accident models (Oyedepo and Makinde, 2009).

\section{Literature Review}

\subsection{Accident Prediction Models(APMs)}

These are very useful tools for estimating the expected number of accidents on entities such as intersections and road sections. These estimates are typically used in the identification of sites for possible safety treatment and in the evaluation of such treatments. Road and Traffic Engineers and Planners can apply the crash prediction model as a tool in safety improvement works and in the design of safer roads. An APM is, in essence, a mathematical equation that expresses the average accident frequency of a site as a function of traffic flow and other site characteristics. Accident Prediction Models (APMs) have been used elsewhere as a useful tool by road Engineers and Planners. Fletcher et al. (2006) found that due to wide differences in traffic mix, road quality, design and road user behaviour, it would be neither valid nor useful to apply simple multiplicative factors or even devise more complex conversion formulae for models developed elsewhere for another country.

\subsection{Accident Risk Factor}

In identifying all factors associated with crashes, it is necessary to select all countermeasures that prevent the crash from occurring. The crash phase is associated with countermeasures that prevent injury from occurring or reduce its severity if it does occur. When thinking about ways of improving safety, therefore, we have to be careful about choosingappropriate measures for the particular problems that exist in a particular country or region. Accident countermeasures that have been found to work well in developed countries cannot always be expected to produce the same results in developing countries. Accident analysis process involves the identification of accident black spot locations, establishment of general patterns of accident, analysis of factors, and site studies (Oyedepo and Makinde, 2009).

\subsection{Causative Factors of Road Traffic Crashes (RTCs)}

The issue of road traffic accidents is one that requires great care in handling as it is hydra-headed in nature. The causes of road traffic accidents are multi-factorial. These factors can be divided broadly into driver factors, vehicle factors and roadway factors. Accidents can be caused by a combination of these factors. Unfortunately, Nigerian highways are arguably one of the worst and most dangerous in the world. Road traffic accidents have physical, social, emotional and economic implications. The global economic cost of road traffic accidents was estimated at $\$ 518$ billion per year in 2003 with $\$ 100$ billion (about $\$ 34$ trillion) of that occurring in poor developing countries (WHO, 2004). The major causes of road traffic accidents could be classified under the following sub-headings namely: Vehicle related factors, Human (Drivers) related factors and Road design factors.

\subsubsection{Vehicle Related Factors}

The tyres, engines, braking system and lights system are among vehicle subsystems which malfunction can cause road accidents (Ovuworiet al., 2010). The vehicle itself is a component of the road traffic system. Consequently its reliability is positively correlated with accident causation on the road network it plies. The reliability of the vehicle is itself a function of the condition of vehicle.

\subsubsection{Human (Driver) Related Factors}

Studies have shown clearly that the singlemost important contributing factor to roadtraffic accidents in Nigeria is the attitude of thedriver to driving code and etiquette. Driver factors solely contribute to about 57 per cent of road traffic accidents and 93 per cent either alone or in combination with other factors. Driver factors in road traffic accidents are all factors related to drivers and other road users. This may include driver behaviour, visual and auditory acuity, decision making ability and reaction speed. Drug and alcohol use while driving is an obvious predictor of road traffic accident, road traffic injury and death. Speeding, travelling too fast for prevailing conditions or above the speed limit, is also a driver factor that contributes to road traffic accidents. 
Driver relatedissues include inexperience, sleepiness and fatigue,faulty preparation, ignorance of highwaycodes or traffic orders, driving under theinfluence of drugs and or alcohol.

\subsubsection{Road design Factors}

According to Asalor (2010), a significant number of vehicular accidents are traceable to the road. Recent studies have demonstrated that the road is another major factor in road accidents in Nigeria. Akinyemi (2009) collected and analyzed 'data on geometric design information system, roadway surface and road side conditions on seven two lane rural roads in the country. It was found out that rural roads in the country have low levels of design consistency, sight distance on and between geometer features as insufficient for stopping and overtaking inadequate traffic control devices. He then argues that their deficiencies are due largely to inadequate road design specification and maintenance. Anyata (2009) on the other hand showed that inadequate drainage could render the road a serious accident threat. Another aspect of the road factor is the general condition of the road itself. Issues of potholes, the indiscriminate location of police check points and the reluctance of the appropriate authorities to continually improve on the condition of the roads are significant in road accidents. Research has shown that careful design and maintenance, with well-designed intersections, road surfaces, visibility and traffic control devices, can result in significant improvements in accident rates.

\subsection{Modified "SCP-AV" (SPCWEG-AV)Model}

The modified SCP-AV model termed SPCWEG-AV model employs a numerical ranking system that assigns relative weights to various parameters which influence road traffic accident. A number of parameters, judged to be representative of road accident vulnerability assessment, are selected and weighted to reflect the relationship between them and their relative importance as regards accident vulnerability. Each of the selected parameters has a given range, which is subdivided into discrete hierarchical intervals. Each interval is assigned a value reflecting the relative degree of accident proneness and the rating points are summed. The final numerical score is divided into segments expressing a relative accident proneness degree. The parameters which make up the acronym SPCWEG-AV are: Spot speed (S), Pavement condition (P), Condition of shoulders (C), Width of the road (W), Elevation(super)/cambering (E), Gradient (G) and Accident Vulnerability (AV) of the segment under consideration. Each of the selected parameter will be given range so as to get the degree of accident vulnerability of the accident prone locations of the road. The typical rating ranges between 1 and 18 and weight from 1 to 6.This is summarized in Table 1.

The SPCWEG-AV accident vulnerability evaluation model is expressed as:

$$
\begin{aligned}
& \text { T.SPCWEG }-A V . I=S_{r} S_{w}+P_{r} P_{w}+C_{r} C_{w}+W_{r} W_{w}+E_{r} E_{w}+G_{r} G_{w} \text { (1) } \\
& \text { Therefore, T.SPCWEG-AV.I }=\sum_{i=1}^{6} \text { Rating }_{\mathrm{i}} \times \text { Weight }_{\mathrm{i}}
\end{aligned}
$$

where,

$T . S P C W E G-A V . I=$ Total $T . S P C W E G-A V . I$ Index i.e. total accident vulnerabilityvalue

$S_{r}=$ Rating assigned to Spot speed

$S_{W}=$ Weight assigned to Spot speed

$P_{r}=$ Rating assigned to Pavement condition

$P_{w}=$ Weight assigned to Pavement condition

$C_{r}=$ Rating assigned to Condition of shoulder

$C_{w}=$ Weight assigned to Condition of shoulder

$W_{r}=$ Rating assigned to Width of the road and shoulder

$W_{w}=$ Weight assigned to Width of the road and shoulder

$E_{r}=$ Rating assigned to Elevation(super)/cambering

$E_{w}=$ Weight assigned to Elevation(super)/cambering

$G=$ Rating assigned to Gradient

$G_{w}=$ Weight assigned to Gradient

$\mathrm{AV}=$ Accident Vulnerability

The SPCWEG-AV index will be used to achieve the measure of accident proneness which is the summation of the products of ratings and weights of each factor. 
Table 1: SPCWEG-AV Rating System and Weights

\begin{tabular}{|c|c|c|c|c|c|}
\hline Parameter & Condition & Classification & Range & Rating & Weight \\
\hline Spot Speed (S) & $\begin{array}{l}\text { Slow } \\
\text { Moderate } \\
\text { Average } \\
\text { Fast } \\
\text { Very Fast } \\
\end{array}$ & $\begin{array}{l}\text { Very Good } \\
\text { Good } \\
\text { Fair } \\
\text { Poor } \\
\text { Very Poor } \\
\end{array}$ & $\begin{array}{c}0-30 \\
30-60 \\
60-90 \\
90-120 \\
120-150 \\
\end{array}$ & $\begin{array}{l}1 \\
2 \\
3 \\
4 \\
5\end{array}$ & 6 \\
\hline Pavement Condition $(\mathrm{P})$ & $\begin{array}{c}\text { Structurally okay } \\
\text { Crack / minor dent } \\
\text { Isolated Potholes } \\
\text { Wavy/ Heavy Surface } \\
\text { Shear/Massive failure }\end{array}$ & $\begin{array}{l}\text { Very Good } \\
\text { Good } \\
\text { Fair } \\
\text { Poor } \\
\text { Very Poor }\end{array}$ & $\begin{array}{c}0-20 \\
20-40 \\
40-60 \\
60-80 \\
80-100\end{array}$ & $\begin{array}{l}1 \\
2 \\
3 \\
4 \\
5\end{array}$ & 5 \\
\hline Condition of Shoulder (C) & $\begin{array}{l}\text { Clean / Clear } \\
\text { Bushy } \\
\text { Small Width } \\
\text { Eroded } \\
\text { Absent }\end{array}$ & $\begin{array}{l}\text { Very Good } \\
\text { Good } \\
\text { Fair } \\
\text { Poor } \\
\text { Very Poor }\end{array}$ & $\begin{array}{c}0-10 \\
10-20 \\
20-30 \\
30-40 \\
40-50\end{array}$ & $\begin{array}{l}1 \\
2 \\
3 \\
4 \\
5\end{array}$ & 4 \\
\hline Width of Pavement / shoulder (W) & $\begin{array}{c}\text { Too small } \\
\text { Small } \\
\text { Normal } \\
\text { Wide } \\
\text { Wider }\end{array}$ & $\begin{array}{c}\text { Very Poor } \\
\text { Poor } \\
\text { Fair } \\
\text { Good } \\
\text { Very Good }\end{array}$ & $\begin{array}{c}0.0-2.8 \\
2.8-5.6 \\
5.6-8.4 \\
8.4-11.2 \\
11.2-14.0\end{array}$ & $\begin{array}{l}5 \\
4 \\
3 \\
2 \\
1\end{array}$ & 3 \\
\hline Elevation(super)/cambering (E) & $\begin{array}{c}\text { Very Bad } \\
\text { Bad } \\
\text { Fair } \\
\text { Good } \\
\text { Very Good }\end{array}$ & $\begin{array}{l}\text { Very Poor } \\
\text { Poor } \\
\text { Fair } \\
\text { Good } \\
\text { Very Good }\end{array}$ & $\begin{array}{l}0.00-0.75 \\
0.75-1.50 \\
1.50-2.25 \\
2.25-3.00 \\
3.00-3.75\end{array}$ & $\begin{array}{l}5 \\
4 \\
3 \\
2 \\
1\end{array}$ & 2 \\
\hline Gradient of Pavement (G) & $\begin{array}{c}\text { Normal } \\
\text { Moderate } \\
\text { Fair } \\
\text { High } \\
\text { Very high }\end{array}$ & $\begin{array}{l}\text { Very Good } \\
\text { Good } \\
\text { Fair } \\
\text { Poor } \\
\text { Very Poor }\end{array}$ & $\begin{array}{c}0-3 \\
3-6 \\
6-9 \\
9-12 \\
12-15\end{array}$ & $\begin{array}{l}1 \\
2 \\
3 \\
4 \\
5\end{array}$ & 1 \\
\hline
\end{tabular}

\subsection{Materials}

III.

Materials And Methods

The Accident records on Akure-Owo highway for six years (2006-2012) were culled from Olabisi (2012) and they were used to identify accident prone locations. That is, locations where accidents have occurred more than once. The analysis of the accident prone locations from the FRSC records is shown in Table 2.

The materials used to determine other parameters were twine, stop watch, plumb and car. The twine was used to determine the elevation(super)/cambering across the road and the gradient along the road; the stop watchwas used to determine the time taken for a particular vehicle to cover a given distance within the road; plumb was used to determine the perpendicularity (horizontal accuracy) of the twine to the determine the elevation (cross slope) or gradient along the road; and car was used to estimate the pavement and shoulder conditions.

Table 2: Accident Vulnerable Locations along Akure-Owo Road

\begin{tabular}{|l|l|l|l|}
\hline Locations & Chainage & Year & Total Number of Accidents \\
\hline Federal Road Safety Corps Area at Akure & $0+000$ & $2006-2012$ & \\
\hline Seebi Holding Area & $1+100$ & $2006-2012$ & 35 \\
\hline Olu Foam Area & $1+200$ & $2006-2012$ & 34 \\
\hline Shagari Area & $1+300$ & $2006-2012$ & 26 \\
\hline Ado-Junction Area & $2+200$ & $2006-2012$ & 36 \\
\hline Federal Govt. Girl's College Area & $3+000$ & $2006-2012$ & 22 \\
\hline Fed. Univ. of Tech. Guest House Area & $3+500$ & $2006-2012$ & 44 \\
\hline Ogbese Market Area & $25+800$ & $2006-2012$ & 44 \\
\hline Ikare-Akoko junction Area at Owo & $47+200$ & $2006-2012$ & \\
\hline
\end{tabular}

\section{Source: Olabisi (2012)}

\subsection{Methods}

The rating and weight method (Alleret al.,1987) was used to obtain the Total SPCWEG-AV Index computation for the seven (7) locations (Tables 4 to 8 ) using a rating system of 1 to 5 for each variable and a weighting system of 1 to 3 in their order of significant contribution to road traffic crashes.

SPCWEG-AV accident vulnerability evaluation model ismathematically expressed as:

T.SPCWEG -AV.I $=S_{r} S_{w}+P_{r} P_{w}+C_{r} C_{w}+W_{r} W_{w}+E_{r} E_{w}+G_{r} G_{w}$ (3)

$S_{r}=$ Rating assigned to Spot speed 
$S_{W}=$ Weight assigned to Spot speed

$P_{r}=$ Rating assigned to Pavement condition

$P_{w}=$ Weight assigned to Pavement condition

$C_{r}=$ Rating assigned to Condition of shoulder

$C_{w}=$ Weight assigned to Condition of shoulder

$W_{r}=$ Rating assigned to Width of the road and shoulder

$W_{w}=$ Weight assigned to Width of the road and shoulder

$E_{r}=$ Rating assigned to Elevation(super)/cambering

$E_{w}=$ Weight assigned to Elevation(super)/cambering

$G=$ Rating assigned to Gradient

$G_{w}=$ Weight assigned to Gradient

$\mathrm{AV}=$ Accident Vulnerability

The higher the SPCWEG-AV Index, the greater the accident proneness at a location. The SPCWEG-AV can be further divided into four categories: low, moderate, high and very high. Accident vulnerability, SPCWEG-AV Index equation was analyzed by imputing the field data into equation 3. Using Statistical Package for Social Sciences (SPSS) Software, a mathematical model for accident vulnerability along Akure-Owo highway was calibrated. The value got from this model when validated using field data was compared with that of parametric model earlier gotten.

\section{Results And Discussion}

Tables 4 to 10 show the SPCWEG-AV index computation as a result of imputing field data at different accident vulnerable locations into the parametric model(see equation 2). Table 4 shows the computation for location1(Seebi Holding Area). The Table shows the spot speed measured on site as $95 \mathrm{~km} / \mathrm{hr}$, the condition of shoulder was eroded, the pavement showed heavy surface, its road width and gradient were normal and its elevation was very good. From Table 1, the rating and weight of $95 \mathrm{~km} / \mathrm{h}$ are 4 and 6 respectively. The multiplication of the two which is SPCWEG-AV index is 24.The index for the condition of shoulder and pavement condition using the same method are 4 and 5 respectively. The Total SPCWEG-AV Index(T.SPCWEG-AV.I) for this location therefore, is 70. The same analysis was performed for locations $2(\mathrm{Olu}$ Foam Area), 3(Shagari Area), 4(Ado-Ekiti junction Area), 5(Federal Government Girl's College Area), 6 (FUTA Guest House Area) and 7 (Ogbese Market Area) to give the Total SPCWEG-AV Indices of 66, 71, 68, 61,71 and 73 respectively. Table 11 also shows the Total SPCWEG-AV Index of an ideal (control) situation as 21 . This means that the accident vulnerability index of a situation where accident will rarely occur is 21 .

Equation 3 could also be re-written as:

$$
\text { T.SPCWEG }-A V . I=6 S_{w}+5 P_{w}+4 C_{w}+3 W_{w}+2 E_{w}+G_{w}(4)
$$

where $6,5,4,3,2$ and 1 are the respective weights of spot speed, pavement condition, condition of shoulder, road of the width, elevation(super)/cambering and gradient of the road (see Table 1).

Table 4: SPCWEG-AV. Index Computation for Location 1 (Seebi Holding Area)

\begin{tabular}{|c|c|c|c|c|c|c|}
\hline Parameters & Field Data & Rating & \multirow[t]{7}{*}{$x$} & Weight & \multirow[t]{8}{*}{$=$} & SPCWEG-AV Index \\
\hline Spot speed (S) & $70 \mathrm{~km} / \mathrm{hr}$ (Average) & 3 & & 6 & & 18 \\
\hline $\begin{array}{c}\text { Pavement } \\
\text { Condition }(\mathrm{P})\end{array}$ & $\begin{array}{c}60 \text { (Wavy/heavy } \\
\text { surface) }\end{array}$ & 4 & & 5 & & 15 \\
\hline $\begin{array}{l}\text { Condition of } \\
\text { Shoulder (C) }\end{array}$ & 62 (Absent) & 5 & & 4 & & 20 \\
\hline $\begin{array}{l}\text { Width of the } \\
\text { Road (W) }\end{array}$ & $8.5 \mathrm{~m}$ (Wide) & 2 & & 3 & & 6 \\
\hline $\begin{array}{c}\text { Elevation(super)/ } \\
\text { cambering (E) }\end{array}$ & $1.5 \%(\mathrm{Bad})$ & 4 & & 2 & & 8 \\
\hline $\begin{array}{l}\text { Gradient of the } \\
\operatorname{road}(\mathrm{G})\end{array}$ & $1.0 \%$ (Normal) & 1 & & 1 & & 1 \\
\hline \multicolumn{5}{|c|}{ T.SPCWEG-AV I } & & 73 \\
\hline
\end{tabular}

Table 5: SPCWEG-AV. Index Computation for Location 2 (Olu Foam Area)

\begin{tabular}{|c|c|c|c|c|c|c|}
\hline Parameters & Field Data & Rating & $x$ & Weight & $=$ & SPCWEG-AV Index \\
\hline Spot speed (S) & $110 \mathrm{~km} / \mathrm{hr}$ (Fast) & 4 & & 6 & & 24 \\
\hline $\begin{array}{c}\text { Pavement } \\
\text { Condition }(\mathrm{P})\end{array}$ & 50 (Isolated Pothole) & 3 & & 5 & & 15 \\
\hline
\end{tabular}


A Parametric Model for Accident Prediction along Akure-Owo Road, Ondo State, Nigeria

\begin{tabular}{|c|c|c|c|c|}
\hline $\begin{array}{l}\text { Condition of } \\
\text { Shoulder (C) }\end{array}$ & 55 (Absent) & 5 & 4 & 20 \\
\hline $\begin{array}{l}\text { Width of the } \\
\text { Road (W) }\end{array}$ & $7.3 \mathrm{~m}$ (Normal) & 3 & 3 & 9 \\
\hline $\begin{array}{l}\text { Elevation(super)/ } \\
\text { cambering (E) }\end{array}$ & $3.2 \%$ (Very good) & 1 & 2 & 2 \\
\hline $\begin{array}{l}\text { Gradient of the } \\
\operatorname{road}(G)\end{array}$ & $3.0 \%$ (Moderate) & 2 & 1 & 1 \\
\hline \multicolumn{4}{|c|}{ T.SPCWEG-AV I } & 72 \\
\hline
\end{tabular}

Table 6: SPCWEG-AV. Index Computation for Location 3 (Shagari Area)

\begin{tabular}{|c|c|c|c|c|c|c|}
\hline Parameters & Field Data & Rating & $x$ & Weight & $=$ & SPCWEG-AV Index \\
\hline Spot speed (S) & $94 \mathrm{~km} / \mathrm{hr}$ (Fast) & 4 & & 6 & & 24 \\
\hline $\begin{array}{c}\text { Pavement } \\
\text { Condition }(\mathrm{P})\end{array}$ & 40 (Isolated pothole) & 3 & & 5 & & 15 \\
\hline $\begin{array}{l}\text { Condition of } \\
\text { Shoulder (C) }\end{array}$ & 31 (Eroded) & 4 & & 4 & & 16 \\
\hline $\begin{array}{l}\text { Width of the } \\
\text { Road (W) }\end{array}$ & $7.25 \mathrm{~m}$ (Normal) & 3 & & 3 & & 9 \\
\hline $\begin{array}{l}\text { Elevation(super)/ } \\
\text { cambering (E) }\end{array}$ & $2.0 \%$ (Fair) & 3 & & 2 & & 6 \\
\hline $\begin{array}{l}\text { Gradient of the } \\
\operatorname{road}(G)\end{array}$ & $1.0 \%$ (Normal) & 1 & & 1 & & 1 \\
\hline \multicolumn{6}{|c|}{ T.SPCWEG-AV I } & 71 \\
\hline
\end{tabular}

Table 7: SPCWEG-AV. Index Computation for Location 4 (Ado-Ekiti junction Area)

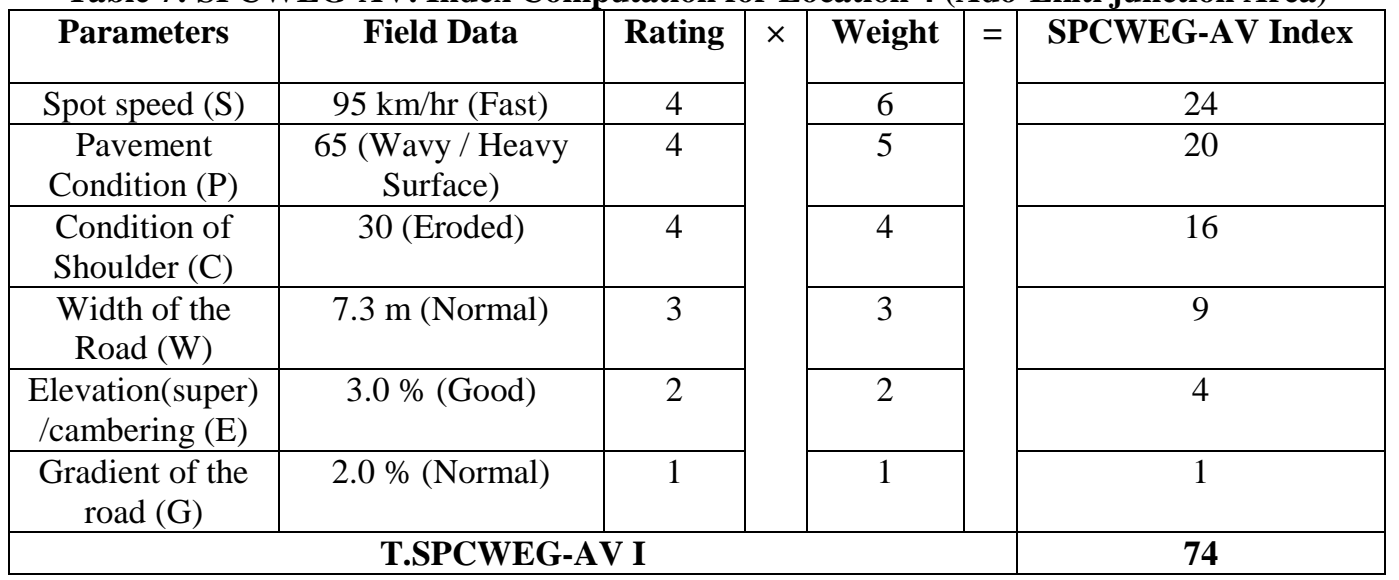

Table 8: SPCWEG-AV. Index Computation for Location 5 (Federal Government Girl's College Area)

\begin{tabular}{|c|c|c|c|c|c|c|}
\hline Parameters & Field Data & Rating & \multirow[t]{7}{*}{$x$} & Weight & \multirow[t]{7}{*}{$=$} & SPCWEG-AV Index \\
\hline Spot speed (S) & 89 km/hr (Average) & 3 & & 6 & & 18 \\
\hline $\begin{array}{c}\text { Pavement } \\
\text { Condition }(\mathrm{P})\end{array}$ & 55 (Isolated Pothole) & 3 & & 5 & & 15 \\
\hline $\begin{array}{l}\text { Condition of } \\
\text { Shoulder (C) }\end{array}$ & 40 (Absent) & 5 & & 4 & & 20 \\
\hline $\begin{array}{c}\text { Width of the } \\
\text { Road (W) }\end{array}$ & $8.0 \mathrm{~m}$ (Normal) & 3 & & 3 & & 9 \\
\hline $\begin{array}{l}\text { Elevation(super) } \\
\text { /cambering (E) }\end{array}$ & $3.2 \%$ (Very good) & 1 & & 2 & & 2 \\
\hline $\begin{array}{l}\text { Gradient of the } \\
\operatorname{road}(\mathrm{G})\end{array}$ & $1.2 \%$ (Normal) & 1 & & 1 & & 1 \\
\hline \multicolumn{6}{|c|}{ T.SPCWEG-AV I } & 65 \\
\hline
\end{tabular}


Table 9: SPCWEG-AV. Index Computation for Location 6 (FUTA Guest House Area)

\begin{tabular}{|c|c|c|c|c|c|c|}
\hline Parameters & Field Data & Rating & \multirow[t]{7}{*}{$x$} & Weight & \multirow[t]{7}{*}{$=$} & SPCWEG-AV Index \\
\hline Spot speed (S) & 108 km/hr (Fast) & 4 & & 6 & & 24 \\
\hline $\begin{array}{c}\text { Pavement } \\
\text { Condition }(\mathrm{P})\end{array}$ & 40 (Isolated pothole) & 3 & & 5 & & 15 \\
\hline $\begin{array}{l}\text { Condition of } \\
\text { Shoulder (C) }\end{array}$ & 65 (Absent) & 5 & & 4 & & 20 \\
\hline $\begin{array}{l}\text { Width of the } \\
\text { Road (W) }\end{array}$ & $7.3 \mathrm{~m}$ (Normal) & 3 & & 3 & & 9 \\
\hline $\begin{array}{c}\text { Elevation(super)/ } \\
\text { cambering (E) }\end{array}$ & $2.0 \%$ (Fair) & 3 & & 2 & & 6 \\
\hline $\begin{array}{l}\text { Gradient of the } \\
\operatorname{road}(G)\end{array}$ & $4.5 \%$ (Normal) & 2 & & 1 & & 2 \\
\hline \multicolumn{6}{|c|}{ T.SPCWEG-AV I } & 76 \\
\hline
\end{tabular}

Table 10: SPCWEG-AV. Index Computation for Location 7 (Ogbese Market Area)

\begin{tabular}{|c|c|c|c|c|c|c|}
\hline Parameters & Field Data & Rating & \multirow[t]{7}{*}{$x$} & Weight & \multirow[t]{7}{*}{$=$} & SPCWEG-AV Index \\
\hline Spot speed (S) & $105 \mathrm{~km} / \mathrm{hr}$ (Fast) & 4 & & 6 & & 24 \\
\hline $\begin{array}{c}\text { Pavement } \\
\text { Condition }(\mathrm{P})\end{array}$ & 60 (Wavy/heavy surface) & 4 & & 5 & & 20 \\
\hline $\begin{array}{l}\text { Condition of } \\
\text { Shoulder (C) }\end{array}$ & 45 (Absent) & 5 & & 4 & & 20 \\
\hline $\begin{array}{l}\text { Width of the } \\
\text { Road (W) }\end{array}$ & $7.3 \mathrm{~m}$ (Normal) & 3 & & 3 & & 9 \\
\hline $\begin{array}{c}\text { Elevation(super)/ } \\
\text { cambering (E) }\end{array}$ & $2.5 \%$ (Good) & 2 & & 2 & & 4 \\
\hline $\begin{array}{l}\text { Gradient of the } \\
\operatorname{road}(\mathrm{G})\end{array}$ & $0.5 \%$ (Normal) & 1 & & 1 & & 1 \\
\hline \multicolumn{6}{|c|}{ T.SPCWEG-AV I } & 78 \\
\hline
\end{tabular}

Table 11: SPCWEG-AV. Index Computation for Control

\begin{tabular}{|c|c|c|c|c|c|c|}
\hline Parameters & Field Data & Rating & \multirow[t]{7}{*}{$x$} & Weight & \multirow[t]{7}{*}{$=$} & SPCWEG-AV Index \\
\hline Spot speed (S) & 30 km/hr (Slow) & 1 & & 6 & & 6 \\
\hline $\begin{array}{c}\text { Pavement } \\
\text { Condition (P) }\end{array}$ & 20 (Structurally okay) & 1 & & 5 & & 5 \\
\hline $\begin{array}{l}\text { Condition of } \\
\text { Shoulder (C) }\end{array}$ & 10 (Clean / Clear) & 1 & & 4 & & 4 \\
\hline $\begin{array}{l}\text { Width of the } \\
\text { Road (W) }\end{array}$ & $11.3 \mathrm{~m}$ (Wider) & 1 & & 3 & & 3 \\
\hline $\begin{array}{l}\text { Elevation(super)/ } \\
\text { cambering (E) }\end{array}$ & $3 / 3.75 \%$ (Very good) & 1 & & 2 & & 2 \\
\hline $\begin{array}{l}\text { Gradient of the } \\
\operatorname{road}(\mathrm{G})\end{array}$ & $0 \%$ (Normal) & 1 & & 1 & & 1 \\
\hline \multicolumn{6}{|c|}{ T.SPCWEG-AV I } & 21 \\
\hline
\end{tabular}

The six (6) categories of accident vulnerability are when:

Total SPCWEG-AV Index is between 0 and 21, accident vulnerability is very low;

Total SPCWEG-AV Index is between 22 and 31, accident vulnerability is low;

Total SPCWEG-AV Index is between 32 and 41, accident vulnerability is moderate;

Total SPCWEG-AV Index is between 42 and 51, accident vulnerability is high;

Total SPCWEG-AV Index is between 52 and 61, accident vulnerability is very high;

Total SPCWEG-AV Index is 62 and above, accident vulnerability is dangerously high.

From the above categorization, it is seen that only one of the locations (Federal Government Girl's College Area) have very high possible occurrence of accident while the remaining five of the locations (Seebi Holding area, Olu Foam area, Shagari area, Ado-Ekiti junction area, FUTA Guest House area, FUTA Guest House area and Ogbese Market area) have dangerously high possible occurrence of accidents. This fact is exemplified by 
the correlation that exists between the degree of accident vulnerability and the frequency of accidents in each of the locations, that is, FUTA Guest House Area $(\mathrm{Ch} .3+500)$ and Ogbese Market Area $(\mathrm{Ch} .25+800)$ recorded the highest occurrence of accident(44 times each) and they also have the highest T.SPCWEG-AV.I value (74 and 76) respectively. Ado-Ekiti junction Area $($ Ch.2+200) and Seebi Holding Area (Ch.1+ 100) have accident occurring 36 and 35 times respectively while their T.SPCWEG-AV.I values are 73 and 71 respectively. Similar pattern runs through all the investigated sections of the road. It is therefore, reasonable to conclude that the parametric model can replicate and predict the occurrence of accidents along our roads. This fact is exemplified by the number of accident records collected by Olabisi (2012) and T.SPCWEG-AV.I for Federal Government Girl's College areawhich are 22 and 65respectively while those of Seebi Holding area, Olu Foam area, Shagari area, Ado-Ekiti junction area, FUTA Guest House area, FUTA Guest House area and Ogbese Market area are 35, 34, 26, 36, 44 and 44 and their T.SPCWEG-AV.I 73, 72, 71, 74, 76 and 78 respectively as shown in Table 12.This situation portends how seriously susceptible these locations are to the occurrence of accidents. It is therefore reasonable to agree that this model can reasonably predict the occurrence of accidents along AkureOwo road and other roads where similar conditions of the highway occur.

Table 12: Comparison of T.SPCWEG-AV.I with accident occurrence at the studied locations

\begin{tabular}{|c|c|c|c|}
\hline Location & $\begin{array}{c}\text { Total SPCWEG-AV } \\
\text { Index. }\end{array}$ & $\begin{array}{c}\text { Total Number of } \\
\text { Accidents }\end{array}$ & Remarks \\
\hline Seebi Holding Area (Ch.1+ 100) & 73 & 35 & Dangerously high \\
\hline Olu Foam Area (Ch.1+200) & 72 & 34 & Dangerously high \\
\hline Shagari Area (Ch.1+300) & 71 & 26 & Dangerously high \\
\hline Ado-Ekiti junction Area (Ch.2+200) & 74 & 36 & Dangerously high \\
\hline $\begin{array}{c}\text { Federal Government Girl's College } \\
\text { Area(Ch.3+000) }\end{array}$ & 65 & 22 & Very high \\
\hline FUTA Guest House Area (Ch.3+500) & 76 & 44 & Dangerously high \\
\hline Ogbese Market Area (Ch.25+800) & 78 & 44 & Dangerously high \\
\hline
\end{tabular}

\section{Conclusion}

Akure-Owo highway has had its fair share of accidents over the years. Previous study by Olabisi (2012) identified seven accident vulnerable points where accidents have occurred more than two times. The parameters considered were: spot speed of vehicles, pavement condition, condition of shoulder, width of the road, elevation(super)/cambering and gradient of the road in order of their weight of accident vulnerability. The analyses and results of these parameters led to the development of Total SPCWEG-AV Index which shows the degree of accident vulnerability. The higher the index, the more vulnerable a section of the road is. This parametric model showed very good correlation between the indices of the model and the frequency of accidents at the investigated points along Akure-Owo road. The results of this research revealed that six (6) out of the seven (7) locations have dangerously high accident vulnerability while one has very high accident vulnerability; FUTA Guest House area(Ch.3+500) and Ogbese market area(Ch.25+800) have the highest T.SPCWEG-AV.I of 76 and 78 respectively; FUTA Guest House Area(Ch.3+500) and Ogbese market Area(Ch.25+800) also have the highest total number accidents (44 times) in each case; the other five locations have their T.SPCWEG-AV.I correlating with the occurrence of accidents in their respective locations; and the SPCWEG-AV parametric model can reasonably predict the occurrence of accidents at these locations and other locations with similar conditions.

\section{Recommendations}

The following recommendations are made in other to reduce the occurrence of accidents along this road in particular and in Nigeria in general:

1. Billboards should be erected in these locations warning the motorists about the dangers locking at the points.

2. The agencies in charge of the construction of roads should pay more attention to the design, supervision, and proper construction of roads and avoid awarding road contracts to incompetent contractors.

3. Highway facilities like drainages, shoulders, highway signs and markings should be provided in appropriate places for the proper functioning of the roads in Nigeria.

4. Road maintenance activities to mend faulty sections of the road on time should be put in place.

5. The Federal Road Safety Commission(FRSC) should intensify their efforts in enlightening road users most especially drivers on the laws guiding road usage and find a way of rigorously enforcing the laws. 
6. Other modes of transportation like the rail lines and waterways should be developed to reduce the pressure onthe road transportation system in the country. This will in turn reduce the level of road accident occurrence in the country

\section{References}

[1]. Akinyemi, E.O. (2009): Contributing Road Factors in Accidents on Rural Roads in Nigeria, inRoad Traffic Accidents in Developing Countries Vol. I Asalor, Onibere and Ovuworie - eds, Joja press, Lagos.

[2]. Aller, L., Bennet, T., Lehr, J.H., \& Petty, R.J. (1987): DRASTIC: A standardized system forevaluating groundwater pollution potential using hydro geologic settings. USEPAdocument no. EPA/600/2-85-018.

[3]. Anyata, B.U. (2009): Highway Drainage and Road Maintenance as Aspects of Highway Safety, University Press, Ibadan.

[4]. Asalor, J.O. (2010): Towards Improved Road Safety in Nigeria.Technical Report No. Rts/00/82/011, Faculty of Engineering, Uni of Benin.

[5]. Asogwa, S.E. (1978): Road traffic accidents: A major public health problem in Nigeria. Public Health, 92(5):237245.

[6]. Ekere, A.U., Yellowe, B.E., Umunne, S.(2005): Mortality patterns in the accident and emergency department of an urban hospital in Nigeria. Nigerian Journal of Clinical Practice; 8(1):14-18.

[7]. Federal Road Safety Commission (FRSC) and Balogun, Y. (2006): Research and Development Opinions, Federal Road Maintenance Agency; pp. 13-16.

[8]. Fletcher,J.P., Baguley, C.J., Sexton,B. and Done, S. (2006): Road accident modeling for highways development and management in developing countries, Main Report: Trials in India and Tanzania, Project Report No:PPR095.

[9]. Kual, A., Sinha, V.S., Pathak, Y.K., Singh, A., Kopoor, A.K., Sharma, S. and Singh, S. (2005): Fatal Road Traffic Accidents, Study of Distribution, Nature and Type of Injury, JIAFM, 27(2):71-78.

[10]. Labinjo, M., Julliard, C., Kobusingye, O.C., Hyder, A.A. (2009): The burden of road traffic injuries in Nigeria: results of a population-based survey. Inj Prev; 16:389-392.

[11]. Olabisi, W.K. (2012): Assessment of Accident Prone Locations along Akure-Owo Highway. Unpublished Postgraduate Diploma Thesis submitted to the Civil Engineering Dept. Federal University of Technology, Akure.

[12]. Odero, W., Garner, P., Zwi, A. (1997): Road traffic injuries in developing countries: a comprehensive review of epidemiological studies. Tropical Medicine \& International Health;2(5):445-460.

[13]. Ovuwori, Onibere and Asalor, J.O. (2010): Road Traffic Accident in Developing Countries Vol.1, Joja Press, Lagos.

[14]. Oyedepo, O.J. and Makinde, O.O. (2009): Regression Model of Household Trip Generation of Ado-Ekiti Township in Nigeria. European Journal of Scientific Research, 28(1):132-140.

[15]. World Health Organisation, WHO (2004): World Report on Road Traffic Injury Prevention: Summary, General. 